\title{
УДК 622.267.7
}

\section{ОСОБЕННОСТИ ПРИМЕНЕНИЯ ПОЛИМЕРНЫХ И ОРГАНИЧЕСКИХ СКРЕПЛЯЮЩИХ СОСТАВОВ ПРИ РЕМОНТЕ ПОДЗЕМНЫХ ГОРНЫХ ВЫРАБОТОК}

\author{
Цибаев Сергей Сергеевич1, \\ cibaevss@kuzstu.ru
}

\section{Зорков Данил Викторович1, zorkovdv@kuzstu.ru}

\author{
Ренев Алексей Агафангелович1, \\ raa@kuzstu.ru
}

\author{
Ванг Цин², \\ qwang@sdust.edu.cn \\ 1 Кузбасский государственный технический университет имени Т.Ф. Горбачева, \\ Россия, 650000, г. Кемерово, ул. Весенняя, 28. \\ 2 Шаньдунский научно-технический университет, \\ КНР, 266590, г. Циндао, Шоссе Циеньваньган, 579.
}

\begin{abstract}
Актуальность. Для предупреждения обрушений, вывалов угля и породы в подготовительных выработках при ремонтных работах широко применяются специальные скрепляющие материалы и технологии, обеспечивающие повышение устойчивости пород в кровле, угля в боках, заполнение видимых раскрытых трещин, пустот. Технология химического упрочнения успешно применяется на отечественных и зарубежных шахтах уже более 30 лет. Сущность этой технологии заключается 8 скреплении неустойчивого массива специальными составами. Область их применения является очень широкой. Известно, что наличие вывалов пород из кровли и боков приводят к образованию куполов, значительному увеличению высоты выработок, образованию глубоких отжимов угля в боках. Наличие куполов, вывалов, глубоких отжимов являются местами слоевых скоплений метана в высоких выработках. В связи с этим скрепляющие составы составляют основу новых технологий при ремонте горных выработок, их перекрепке, ликвидации завалов и куполов.

Цель: разработка проектных решений и обоснование параметров упрочнения массива горных пород современными скрепляющими составами при ремонте и восстановлении подземных горных выработок.

Методы: натурные исследования, статистическая обработка результатов экспериментальных исследований.

Результаты. Рассмотрен вопрос применения скрепляющих материалов при ремонте и перекрепке горных выработок. Произведен комплексный анализ различных по основному скрепляющему компоненту скрепляющих составов, учитывающий их характеристики, область применения и требования к оборудованию для производства работ. Выделено восемь основных групп составов. Предложена технологическая схема упрочнения пород кровли и боков на участках сопряжений подготовительных горных выработок с использованием инъекционного упрочнения полиуретановыми составами.
\end{abstract}

\section{Ключевые слова:}

Устойчивость горных выработок, ремонт горных выработок, анкерное крепление, скрепляющие составы, химическое упрочнение.

\section{Введение}

Ведение горных работ в зонах неустойчивых горных пород сопряжено с повышенной опасностью. Наиболее характерные места возникновения таких зон - геологические нарушения. При работе в таких зонах возникает высокая вероятность массовых вывалов пород в горные выработки, что может привести к травмам горнорабочих и повреждению оборудования. Кроме того, эти зоны в виду сильной трещиноватости, как правило, обладают повышенной газо- , воздухо- и водопроницаемостью, что помимо вывалов также представляет серьезную опасность.

Проблемы возникают не только при неустойчивых вмещающих породах, но и угле. К проблемным можно отнести участки со слабым, склонным к интенсивному отжиму углем и с сильно трещиноватым кливажистым углем [1-3]. Проблемными местами, требующими дополнительного упрочнения даже при относительно устойчивых породах, также являются:
- кровля и бока передовых выработок, переходимых очистным забоем;

- сопряжения очистных забоев с выработками, оконтуривающими выемочный столб;

- демонтажные камеры;

- участки выемочного столба и целиков, попадающие в зоны повышенного горного давления (ЗПГД).

Следует отметить, что описанные выше зоны встречаются практически на каждой шахте. На многих шахтах ведение горных работ осложнено большим количеством геологических нарушений, которые периодически снижают эффективность подготовительных и очистных работ. Наибольшее распространение в качестве таких составов получили синтетические двухкомпонентные смолы [4]. В отечественной угольной промышленности технология получила широкое применение относительно недавно, хотя положительные результаты ее применения в Кузбассе были получены еще в 80-х гг. прошлого века. 


\section{Анализ составов и областей применения} современных скрепляющих составов горных город

Скрепляющие составы получают путем соединения двух химических компонентов, отверждающихся в холодном состоянии при их соединении и обеспечивающих необходимую прочность адгезии к горным породам. В качестве основного компонента состава обычно используют полимерные смолы: полиэфирную, карбамидоформальдегидную фенолоформальдегидную, эпоксидную и пр. Вторым компонентом состава является отвердитель смолы с различными добавками и наполнителями, улучшающими технологические свойства и качество упрочнения горного массива.

Скрепляющие материалы должны обеспечивать их применение по двух- или однокомпонентной схеме, удовлетворять основному способу их применения нагнетанию в массив.

Для упрочнения пород нагнетанием чаще всего применяют двухкомпонентную схему подачи состава, при которой каждый из компонентов (смола и отвердитель) подаются к пробуренному в породе шпуру раздельно, каждый по своему шлангу, а смешивание производится уже в шпуре поступлением в трещины $[5,6]$. Иногда нагнетание скрепляющих составов (на основе карбамидных смол, вяжущих, цементов) производят по однокомпонентной схеме, при которой смешивание обоих компонентов осуществляется предварительно перед насосом.

Основным показателем допустимости скрепляющего состава для упрочнения горных пород служит критерий его адгезионной прочности к субстрату (породе) [7]. На основании опытных работ в зарубежной и отечественной практике приняты следующие необходимые и достаточные величины адгезионной прочности полимерного связующего состава к породам по требуемой величине деформации растяжения: не менее 1,5 МПа для пластичных составов (типа полиуретановых) и не менее 2,0 МПа для относительно хрупких составов. Эти критерии прочности справедливы для любого типа горных пород и их горно-геологического и эксплуатационного состояния [8]. Скрепляющие составы должны учитывать физико-механические и физикохимические свойства горных пород.

Склонные к трещинообразованиям и обрушениям породы большей частью представляют собой алевролиты и аргиллиты - углистые, глинистые или песчаные сланцы, которые могут содержать прослойки угля, глины, известняка, включающего соли угольной кислоты (карбонаты) песчаника и других минералов. Иногда встречаются также сыпучие породы мелких фракций, породы типа «мыльник» с ярко выраженными зеркалами скольжения породы, представляющие прочные угловатые куски неправильной формы, сцементированные непрочным углисто-глинистым минералом [9].

При выборе скрепляющих составов учитывается естественное состояние упрочняемых горных пород, характеризуемое их химико-минералогическим составом (Ac, $\mathrm{Na}+, \mathrm{Ca}++$ и пр.) и водородным показателем $\mathrm{pH}$ водной вытяжки, который может колебаться в широких пределах: 1-2 - кислые воды, 10-12 - щелочные воды.

Важное значение для выбора скрепляющего состава имеет преобладающая степень величины раскрытия трещин: если она мала (менее 1 мм), то прочность соединения блоков определяется их фрикционной связью и характеризуется главным образом адгезией состава к породе; если значительна (2-3 мм), во внимание принимается также когезионная прочность самого состава, так как система «субсстрат-адгезив» (порода - связующий состав) работает как композит из двух материалов [10]. В этом случае показатель прочности связующего состава в отвержденном виде должен приближаться к соответствующему показателю породы.

Положительным качеством скрепляющего состава является его вспенивание - расширение (увеличение в объеме) в процессе полимеризации. Вспенивание приводит к возникновению дополнительных, распорных сил между блоками пород, способствующих их удержанию в равновесном состоянии.

Для сопротивления сдвигающим деформациям от возможного воздействия проводимых вблизи зоны упрочнения горных работ, в т. ч. динамического характера (например, взрывных), к скрепляющим составам предъявляется требование пластичности в процессе отверждения и эластичности в отвержденном виде [11, 12].

В зависимости от свойств упрочняемого и/или заполняемого массива, требуемого эффекта, применяют следующие типы составов:

- мочевинные;

- карбомидные;

- магнезиальные;

- на основе фенолоформальдегидных смол;

- органоминеральные;

- цементосодержащие;

- фенольные;

- полиуретановые.

На основе мочевины применяются следующие скрепляющие составы: «Iglaneige-PL», «Mariklei». Скрепляющий состав «Igloneige-PL» представляет собой двухкомпонентную мочевинную пену. Мочевинная смола смешивается с катализатором, получается мочевинная пена. Состав характеризуется следующими данными:

- быстро вспенивается и хорошо заполняет пустоты;

- обладает высокими герметизирующими качествами;

- антистатические свойства пены;

- время реакции при смешивании компонентов $-0,5$ мин;

- количество исходного материала для получения $1 \mathrm{~m}^{3}$ пены - 35кг.

Состав имеет следующие области применения:

- заполнение закрепленных пустот;

- возведение вентиляционных перемычек;

- быстрое возведение изоляционных перемычек при авариях.

Мочевинный клей «Mariklej» предназначен в основном для упрочнения угля. Характеризуется хорошей адгезией, отсутствием агрессивности и токсичности. «Mariklej» рекомендуется для упрочнения уг- 
лепородного массива при восстановлении аварийных участков горных выработок.

Карбамидные скрепляющие составы применяются для опережающего упрочнения угольных массивов, пород в выработках при очистных работах. Карбамидоформальдегидные составы на основе смол типа КФ-МТ, КФ-Ж, МФ-17 нашли довольно широкое применение, хотя практика показала их меньшую универсальность по сравнению с пенополиуретановыми составами. Составы холодного отвержения приготавливаются на основе карбамидоформальдегидных смол и отвердителя в виде 5-10\%-х растворов ортофосфорной кислоты, хлористого железа или щавелевой кислоты. Нагнетание состава в массив производится по однокомпонентной схеме через шпур. Для повышения пластичности карбамидных составов разработаны специальные пластификаторы на основе акрилатных латексов. Установлено, что при введении в состав смолы КФ-Ж и отвердителя $\mathrm{FeCl}_{3} 30$ \% латекса МБМ-5с эластичность состава существенно повышается.

Скрепляющие магнезиальные составы рекомендуется применять для опережающего упрочнения разрушенных (трещиноватых) пород и угля в следующих случаях:

- при проходке, поддержании и ремонте основных и подготовительных выработок;

- в монтажных и демонтажных камерах.

Упрочнение нарушенных трещинами горных пород и угля магнезиальным скрепляющим составом (вяжущим) является профилактической мерой, препятствующей трещинообразованию и обрушению неустойчивых пород в нарушенных зонах. Технология физико-химического упрочнения основана на принудительном нагнетании через шпуры в трещиноватые породы (с раскрытием трещин 1,5 мм и более) жидкого магнезиального состава, который при отверждении связывает блоки пород или угля между собой, повышая общую устойчивость углепородного массива. Отверждение магнезиального состава (вяжущего) происходит в результате химической реакции при смешивании хлористого магния $\mathrm{MgCl}_{2}$ и окиси магния $\mathrm{MgO}$. В зависимости от условий упрочнений состав может нагнетаться в шпуры с предварительно заложенными в них армирующими элементами (металлическими, полимерными, деревянными стержнями и т. д.), которые закрепляются по всей длине магнезиальным вяжущим и повышают несущую способность кровли благодаря ее дополнительному армированию. К достоинствам магнезиального вяжущего относятся высокие адгезионные и прочностные характеристики, хорошая проникающая способность, отсутствие усадки после отверждения, низкая стоимость по сравнению с другими скрепляющими составами, возможность длительного хранения исходных компонентов [13]. Однако основным преимуществом магнезиального вяжущего является то, что химический состав пород и количество влаги в них не оказывают существенного влияния на процесс отверждения нагнетаемого состава и на качество упрочнения.
Нагнетание магнезиальных скрепляющих составов в массив производится по однокомпонентной схеме.

Из известных в мировой и отечественной практике способов повышения устойчивости горного массива наиболее прогрессивным является упрочнение пород и угля скрепляющими составами на основе фенолоформальдегидных синтетических смол. Применение скрепляющих составов на основе фенолоформальдегидной смолы предусматривает:

- предупреждение обрушений, вывалов угля и породы в подготовительных и очистных забоях;

- повышение устойчивости пород и угля на сопряжениях выработок;

- повышение устойчивости пород и угля в выработках в зонах влияния геологических нарушений.

Из опытно-промышленного применения скрепляющего состава на основе фенолоформальдегидных смол $[14,15]$ установлено, что через 1,5-3 часа после нагнетания горный массив приобретает устойчивость, обеспечивающую безопасность и безаварийность продолжения работ по очистной выемке угля и проведению капитальных и подготовительных горных выработок.

Органоминеральные скрепляющие составы позволяют быстро и эффективно производить заполнение пустот, вывалов, осуществлять заделку трещин. Из органоминеральных составов на отечественных шахтах применяются: «Геофлекс», «Tekflex», «Геофом».

Органоминеральная смола «Геофлекс» состоит из двух жидких компонентов: А и В. «Геофлекс» относится к категории моментальных клеев. Не увеличивается в объеме после реакции компонентов. Подача состава в массив осуществляется насосной установкой, состоящей из двух одинаковых насосов.

Область применения:

- упрочнение трещиноватого массива;

- заполнение трещин без разрушения угля и породы.

Состав «Tekflex» состоит из двух компонентов: жидкого полимерного компонента и цементного порошка. Состав применяется с помощью пневматического насоса. Наносится после перемешивания на обрабатываемую поверхность выработки путем аэрозольного распыления. При производстве ремонтных работ в горных выработках состав может применяться:

- для удержания поверхности пород кровли от обрушения;

- удержания поверхности угля в боках выработок от вывалов;

- замены решетчатой затяжки;

- использования в качестве набрызг-бетона;

- защиты поверхностей выработок от атмосферных воздействий.

Состав «Геофом» - органоминеральная смола, состоит из двух жидких компонентов. Одним компонентом является модифицированное жидкое стекло A, компонент В - модифицированный изоционат [16]. Составы подают отдельно по своим шлангам до смесителя. В смесителе перемешиваются и далее путем набрызга наносятся на подготовленную поверхность 
выработки. Реакция компонентов происходит с увеличением объема состава. Состав относится к расширяющимся. После смешивания смола вспенивается в течение нескольких секунд. При производстве ремонтных работ состав «Геофом» может применяться:

- для заполнения пустот;

- заполнения куполов;

- заполнения открытых трещин;

- связывания разрушенных пород.

Благодаря простоте подготовки состава для подачи в массив, отсутствия токсичности, возгораемости получают широкое применение на шахтах следующие иементосодержащие скрепляющие материалы: «Текбленд», «Текфом», «Защита», «Барьер», «Распор».

Скрепляющий состав «Текбленд» - это однокомпонентный состав в виде цементного порошка серого цвета. После смешивания с водой и отверждения образуется легкий бетон. Подача водоцементной смеси к месту выполняемых работ производится при помощи насосного агрегата. Состав «Текбленд» не горюч, не токсичен, не взрывоопасен. На угольных шахтах данный скрепляющий состав получил широкое применение при возведении безврубовых, взрывоустойчивых, изоляционных перемычек. Основная область применения состава:

- возведение взрывоустойчивых противопожарных перемычек;

- возведение водоупорных, изолирующих перемычек;

- заполнение закрепленного пространства и куполов в выработках.

«Текфом» - это специальная цементная смесь, образующая легкую вспененную массу - пенобетон. Отличается от «Текбленда» пригодностью состава к применению высокомеханизированной технологии подачи и укладки пенобетона. В связи с этим «Текфом» рекомендуется к использованию при ремонте горных выработок для заполнения вывалов в кровле и боках выработок, куполов в кровле, глубоких отжимов в боках.

Скрепляющий состав «Защита» представляет собой герметик, имеющий двухкомпонентный состав: сухую цементную смесь и жидкую эмульсию полимерного латекса. Применяется при ремонтах для покрытия поверхностей выработок с повышенной трещиноватостью, с открытыми трещинами. Состав обладает высокими адгезионными свойствами, имеет высокую разрывную прочность (до 4,54 МПа). Возведенное покрытие обладает защитно-поддерживающими свойствами. Нагнетание состава в массив производится по двухкомпонентной схеме.

Скрепляющий состав «Барьер» поставляется в виде цементного порошка светло-серого цвета. После смешивания с водой образуется «легкий» бетон. Является негорючим, не взрывоопасным, не токсичным материалом. При ремонте и перекрепке горных выработок рекомендуется для заполнения закрепленного пространства, пустот в боках и кровле, вывалов и куполов. Известен также под названием «пенобетон».
Особенность получения пенобетона состоит в том, что воздушные ячейки в массе бетона образуются путем физического перемешивания воздуха с цементным раствором. Материал совершенно не токсичен.

На угольных шахтах России из фенольных вспенивающихся скрепляющих составов в настоящее время широкое применение получают «Карбофил» и «Mariflex» (Марифлекс).

«Карбофил» обладает высоким фактором вспенивания и высокой скоростью реакции смешивания. Состоит из двух жидких компонентов фенольной смолы и катализатора. После смешивания и выхода из смесителя компоненты увеличиваются в объеме и создают пенную массу. Окончательно вспенивание и расширение объема до максимальной величины происходит за 3 минуты. Область применения состава:

- заполнение вывалов в выработках в кровле и боках;

- заполнение пустот в выработках с целью предотвращения скопления метана.

Скрепляющий состав «Марифлекс» представляет собой двухкомпонентную негорючую пену, обладающую изолирующими свойствами и относительно высокой прочностью. Компонентами состава являются смола фенольная и катализатор. При смешивании образуют плотную, мгновенно увеличивающую свой объем и быстро твердеющую пену. Рабочие свойства пена приобретает в течение 5 мин. Возведенное покрытие заменяет решетчатую или сетчатую затяжку в кровле и боках ремонтируемых выработок. Основная область применения состава «Марифлекс»:

- заполнение пустот в выработках при анкерном креплении выработок;

- заполнение вывалов, куполов, трещин в кровле и боках;

- применение для набрызг-покрытия.

Полиуретановые составы получают наиболее широкое применение на угольных шахтах для упрочнения пород и угля как в очистных, так и в подготовительных выработках $[17,18]$. Разработано два вида полиэфирной части смолы - нормальная, со сроком схватывания 20-30 мин, и ускоренная, отверждающаяся за 1,5-2 мин. Ускоренная система применяется в экстренных случаях. Полиуретаны являются синтетическими полимерами, нашедшими свое применение в различных областях как жесткие или эластичные материалы, не вспененные или пенопласты. Для укрепления горных пород в подземных выработках были созданы полиуретановые системы, сочетающие в себе безопасность, простоту и надежность в применении. Применение полиуретана в подземных условиях обусловлено следующими важными свойствами:

- упругость и пластичность;

- увеличение объема благодаря вспениванию;

- короткое задаваемое время отверждения;

- хорошая адгезионная способность по отношению к породам и углю;

- наличие высоких когезионных свойств;

- низкая вязкость; 
- отсутствие выделения воды или растворителя при отверждении.

Полиуретан, в отличие от неорганических вяжущих составов (цемент и т. п.) и других синтетических смол, обладает необходимой упругостью и пластичностью. Это способствует тому, что отвержденный состав при смещениях массива не теряет контакта с породой и попрежнему может выполнять свою функцию. Благодаря увеличению объема состава при смешивании компонентов расход материала уменьшается пропорционально кратности вспенивания. Увеличение объема можно использовать для самонагнетания смолы [19]. Если скважины заделываются после загрузки смолы, то увеличение объема смеси приводит к росту давления в скважине, что в свою очередь способствует проникновению смолы в разрушенный массив. Важное значение для укрепления массива имеет хорошая проникающая способность синтетической смолы, которая определяется вязкостью компонентов. После смешивания компонентов низкая начальная вязкость состава резко повышается. Это свойство имеет то преимущество, что при креплении массива повышенной трещиноватости предотвращается перетекание смеси в зоны, слишком удаленные от подлежащих упрочнению участков. На определенном расстоянии от места нагнетания смесь сама создает себе препятствие для дальнейшего внедрения в массив.

Анализ применения фенолоформальдегидных смол на отечественных угольных шахтах показывает, что наибольшее применение получают полиуретановые составы в виде:

- химических ампул для сталеполимерных анкеров;

- пурпатронов для упрочнения выработок на локальных участках;

- смол для упрочнения пород и угля путем нагнетания смол в массив.

Наибольшее распространение получили следующие серии полиуретановых смол: «Беведол-Беведан» («Bevedol-Bevedan») типы S, WF, WFA и др.; «КарбокрэкСил Н» типы А и В; «КарбоСтоп-И».

В результате анализа характерных особенностей всех рассмотренных скрепляющих составов сформированы 13 типовых ситуаций, где составы достигают наибольшего эффекта при применении. Полученные данные сведены в табл. 1.

Таблица 1. Область применения скрепляющих составов

Table 1. Fastening compounds application area

\begin{tabular}{|c|c|c|c|c|c|c|c|c|c|c|c|}
\hline \multirow[b]{3}{*}{$\begin{array}{c}\text { Достигаемый наибольший эффект по применению } \\
\text { The greatest application effect }\end{array}$} & \multicolumn{11}{|c|}{ Наименование состава/Compound } \\
\hline & \multicolumn{2}{|c|}{$\Pi / \mathrm{P}$} & \multirow{2}{*}{ 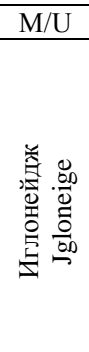 } & \multicolumn{2}{|c|}{$\mathrm{O} / \mathrm{O}$} & \multicolumn{3}{|c|}{$\Phi / \mathrm{Ph}$} & \multicolumn{3}{|c|}{ Ц/C } \\
\hline & 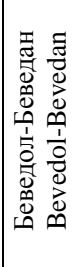 & 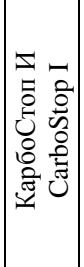 & & 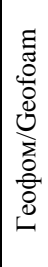 & 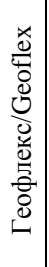 & 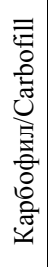 & 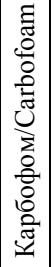 & 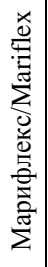 & 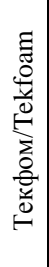 & 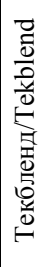 & 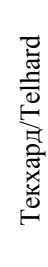 \\
\hline $\begin{array}{l}\text { Укрепление обводненной и водоносной породы } \\
\text { Water-saturated rocks fastening }\end{array}$ & + & & & & & & & & & & \\
\hline $\begin{array}{l}\text { Упрочнение массива в очистных забоях и их сопряжениях } \\
\text { Rock fastening at longwall and crossway areas }\end{array}$ & + & & & & + & + & & & & & \\
\hline $\begin{array}{l}\text { Гидроизоляция } \\
\text { Waterproofing }\end{array}$ & + & + & & + & & & & & & & \\
\hline $\begin{array}{l}\text { Санация обводненных шахтных стволов } \\
\text { Watered shafts sanitation }\end{array}$ & + & & & & & & & & & & \\
\hline $\begin{array}{l}\text { Упрочнение грунта } \\
\text { Soil fastening }\end{array}$ & & + & & & & & & & & & \\
\hline $\begin{array}{l}\text { Герметизация буровых скважин } \\
\text { Borehole sealing }\end{array}$ & & + & & & & & & & & + & \\
\hline $\begin{array}{l}\text { Упрочнение массива в подготовительных выработках } \\
\text { Roadways and incline rock fastening }\end{array}$ & + & & & & + & & & & & & \\
\hline $\begin{array}{l}\text { Заполнение систем трещин в нарушенном массиве } \\
\text { Systems of cracks filling in the disturbed massif }\end{array}$ & & & & + & + & & & + & & & \\
\hline $\begin{array}{l}\text { Заполнение пустот и куполов } \\
\text { Voids and domes filling }\end{array}$ & & & + & + & & + & + & + & + & + & \\
\hline $\begin{array}{l}\text { Tампонаж угольного массива для уменьшения газопроницаемости } \\
\text { Coal massif plugging to reduce gas permeability }\end{array}$ & & & & & + & & & & & & \\
\hline $\begin{array}{l}\text { Анкерование горных пород с упрочнением окружающего массива } \\
\text { Surroundin massif ancorage with fastening effect }\end{array}$ & & & & & + & & & & & & \\
\hline $\begin{array}{l}\text { Заполнение и уплотнение перемычек } \\
\text { Lintels filling and sealing }\end{array}$ & & & & + & & + & & + & + & + & + \\
\hline $\begin{array}{l}\text { Возведение изолирующих полос, искусственных целиков } \\
\text { Artificial pillars construction }\end{array}$ & & & & & & & & & + & + & + \\
\hline
\end{tabular}

П-полиуретановые; $M$-мочевинные; О-органоминеральные; $\Phi$ - фенольные; Ц-иементосодержащие.

$P$-polyurethane; $U$-urea; $O$-organomineral; $P h$-phenol; $C$-cement-bearin. 


\section{Технологическая схема производства работ}

\section{по упрочнению массива пород}

при ремонте выработок

Одним из наиболее распространённых явлений при длительной эксплуатации горных выработок является деформация углепородного массива на участках сопряжений выработок. Для предотвращения разрушения приконтурного массива пород рекомендуется произвести упрочнение боков выработок на сопряжениях скрепляющими составами типа «БеведолБеведан» («Bevedol-Bevedan») со следующими параметрами (рис. 1), составленными с учётом требований нормативных документов и мирового опыта проведе- ния работ по инъекционному упрочнению массивов пород [20]:

- радиус упрочнения 1500 мм;

- два шпура в вертикальном ряду;

- расстояние между шпурами в ряду 1700 мм;

- расстояние между рядами шпуров 2300 мм;

- угол наклона шпуров верхнего ряда 13;

- длина шпуров нижнего ряда 4500 мм;

- длина шпуров верхнего ряда 4610 мм;

- глубина герметизации 1500 мм;

- давление нагнетания 2-5 МПа.

\section{$B-B$}

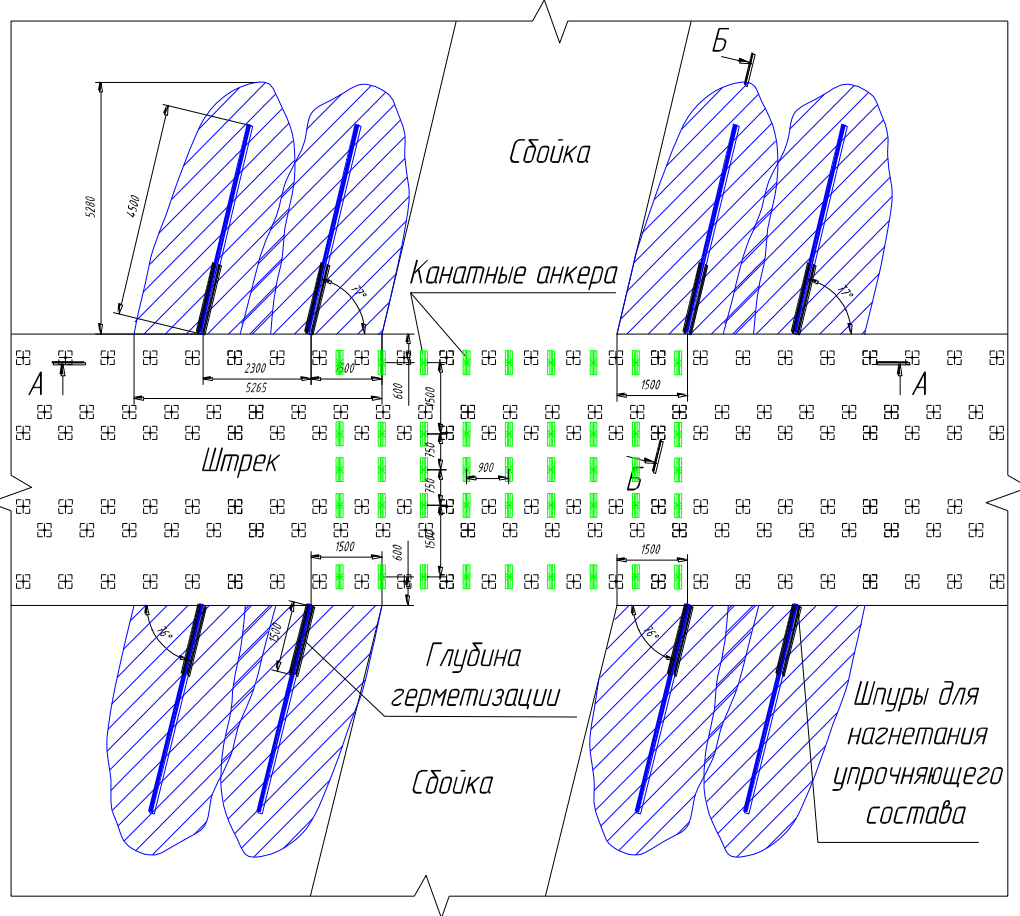

$A-A$
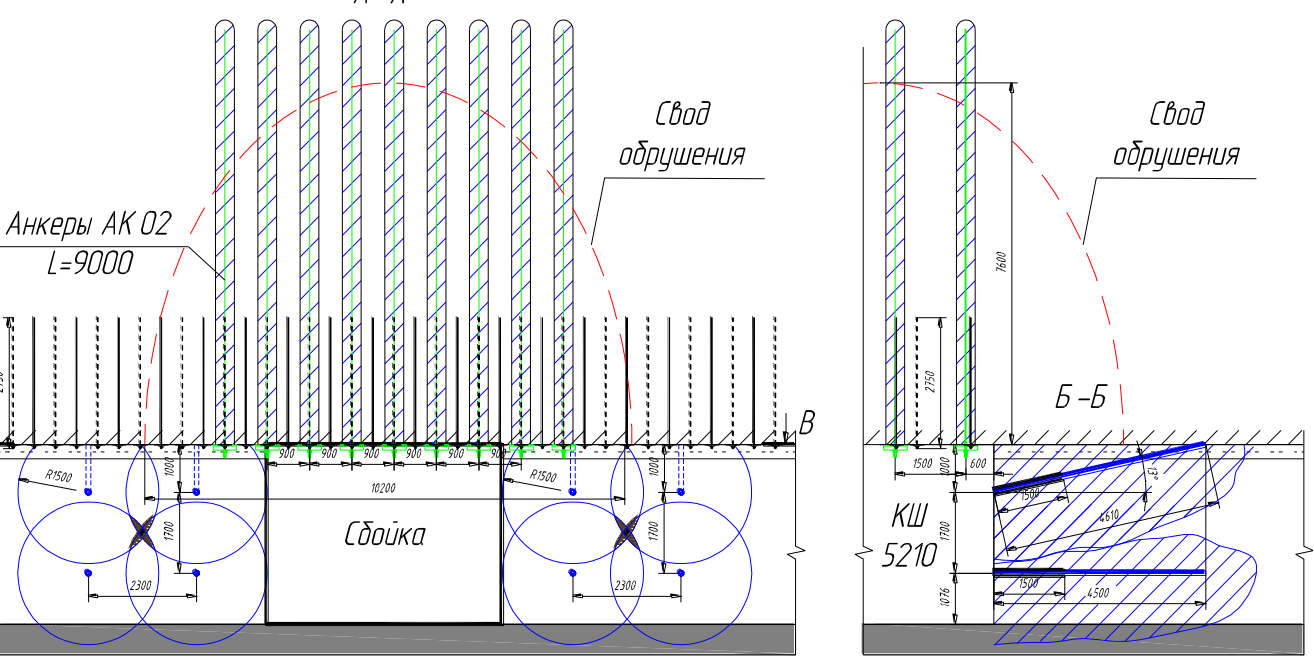

Pис. 1. Паспорт упрочнения боков и кровли штрека на сопряжении с помощью скрепляющего состава «БеведолБеведан» («Bevedol-Bevedan»)

Fig. 1. Design project of roadway walls and roof strengthening using the fastening compound «Bevedol-Bevedan» 
Анализ опыта применения скрепляющих составов при ремонте и восстановлении горных выработок показывает, что для составов с двумя компонентами, в том числе «Беведол-Беведан», широкое применение получают пневматические двухкомпонентные насосы типа SK90 1:1 (рис. 2). В табл. 2 приведены основные технические характеристики насоса SK90 1:1.

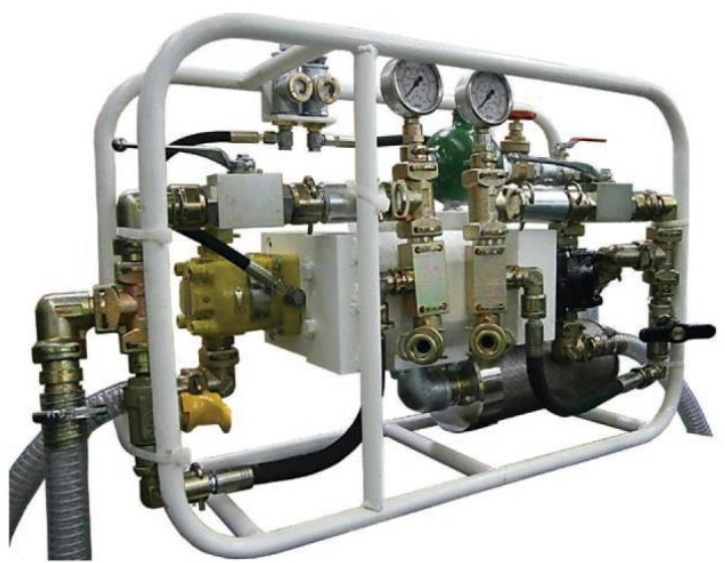

Puc. 2. Общий вид пневматического насоса SK90 1:1

Fig. 2. Pneumatic pump SK90 1:1 general view

Таблица 2. Техническая характеристика пневматического двухкомпонентного насоса SK90 1:1

Table 2. Two-component pneumatic pump SK90 1:1 technical data

\begin{tabular}{|l|c|}
\hline \multicolumn{1}{|c|}{ Показатель/Mark } \\
\hline $\begin{array}{l}\text { Рабочее давление пневмопривода, бар } \\
\text { Pneumatic drive pressure, bar }\end{array}$ & $4-7$ \\
\hline $\begin{array}{l}\text { Максимальный расход воздуха, м³/мин } \\
\text { Махіmum air consumption, m³in }\end{array}$ & 8 \\
\hline $\begin{array}{l}\text { Максимальное давление нагнетания, бар } \\
\text { Махіmum discharge pressure, bar }\end{array}$ & 160 \\
\hline $\begin{array}{l}\text { Tемп подачи полимерного состава, л/мин } \\
\text { Feeding perfomance, 1/min }\end{array}$ & $7,5-20,0$ \\
\hline $\begin{array}{l}\text { Paзмеры, мм } \\
\text { Dimensions, mm: } \\
\text { длина/length } \\
\text { ширина/width } \\
\text { высота/ height }\end{array}$ & 1200 \\
\hline $\begin{array}{l}\text { Macca, кг } \\
\text { Weight, kg }\end{array}$ & 450 \\
\hline
\end{tabular}

Значение радиуса упрочнения зависит от давления при нагнетании, трещиноватости упрочняемого массива и интенсивности заполнения трещин составом. Его значение для конкретных условий может быть установлено путём контрольного нагнетания состава в шпур. Важное условие при проектировании схемы расположения шпуров - радиусы всех шпуров долж-

\section{СПИСОК ЛИТЕРАТУРЫ}

1. Анализ типовых форм деформаций приконтурного углепородного массива и особенности восстановления крепления горных выработок / С.С. Цибаев, А.А. Ренев, Ванг Цин, Юй Фэн-Хай // Известия Томского политехнического университета. Инжиниринг георесурсов. - 2021. - Т. 332. - № 11. C. 223-232.

2. Analysis of rock mass and anchor support elements deformations during the long-term maintenance of mine workings / S. Tsibaev, A. Renev, R. Zainulin, A. Kucherenko // Vth International Innovative Mining Symposium. - 2020. - V. 174. URL: ны пересекаться (тёмные области на сечении А-А на рис. 1)

Диаметр шпуров, применяемых для упрочнения массива, равен 43 мм. Расстояние между шпурами в ряду определяется в зависимости радиуса упрочнения:

$$
B \leq 2 R_{\mathrm{y}}-0,7,
$$

где $B$ - расстояние между шпурами в ряду, м; $R_{\mathrm{y}}$ - paдиус упрочнения, м.

Расстояние между рядами шпуров в зависимости от высоты бока принимается от 1,0 до 2,5 м. Ширина упрочняемой зоны должна быть не менее 5 м. Давление при нагнетании в пласт принимается от 2 до 5 МПа. Конкретное значение принимается по фактическому состоянию упрочняемого пласта при условии недопущения его дополнительного разрушения от напора при нагнетании. Угол наклона шпуров верхнего ряда принимается от 10 до $20^{\circ}$. Положение этих шпуров должно обеспечивать укрепление угля и ложной кровли. Длина шпуров верхнего ряда принимается в зависимости от угла их наклона. Для предотвращения выхода состава в выработку глубина герметизации должна быть не менее принятого для конкретного случая радиуса упрочнения. Она принимается от 1,3 до 2,3 м.

\section{Выводы}

1. Рассмотрен вопрос применения скрепляющих материалов при ремонте и перекрепке горных выработок. Скрепляющие составы, применяемые в отечественной и зарубежной угольной промышленности, разделяются на восемь групп по основному скрепляющему компоненту. Произведена оценка характеристик, области применения составов, требований к оборудованию для производства работ.

2. Применение скрепляющих составов в отечественной угольной промышленности сопряжено с отсутствием единой нормативной и методической документации, описывающей параметры, режимы и схемы производства работ по упрочнению массива.

3. Предложено проектное решение по упрочнению массива пород на участках сопряжений подготовительных выработок с использованием инъекционного нагнетания полиуретановых скрепляющих составов.

Исследование выполнено при финансовой поддержке государственного задания Министерства науки и выстего образования Российской Федераиии (№ 075-03-2021 138/3).

https://doi.org/10.1051/e3sconf/202017401001 (дата обращения 15.10.2021)

3. Renev A., Tsibaev S., Kalinin S. The evaluation of negative anthropogenic factors subjection on bolts stability and surrounding massif deformations // Coal in the 21st Century: Mining, Intelligent Equipment and Environment Protection: 9th ChinaRussia Symposium. - 2018. - P. 359-364. URL: https://doi.org/10.2991/coal-18.2018.67 (дата обращения 15.10.2021).

4. Snuparek R., Soucek K. Polyurethane geocomposites. mechanical properties and deformation // International Mine Water Association Proceedings. - Sevilla, Spain, 1999. - P. 657-661. 
5. Shreedharan S., Kulatilake P.H.S.W. Discontinuum - equivalent continuum analysis of the stability of tunnels in a deep coal mine using the distinct element method // Rock Mechanics And Rock Engineering. - 2016. - № 49 (5). - P. 1903-1922. URL: https://www.researchgate.net/publication/284103706_Discontinuu m-Equivalent_Continuum_Analysis_of_the_Stability_of Tunnels_in_a_Deep_Coal_Mine_Using_the_Distinct_Element_M ethod (дата обращения 15.10.2021).

6. Sabri M.M., Shashkin K.G. Improvement of the soil deformation modulus using an expandable polyurethane resin // Magazine of Civil Engineering. - 2018. - V. 83 (7). - P. 222-234. DOI: 10.18720/MCE.83.20

7. Rock pressure manifestation in development workings advanced in a thick coal seam / K. Filimonov, D. Zorkov, S. Tsibaev, A. Kucherenko // Vth International Innovative Mining Symposium. 2020 . - V. 174. URL: https://doi.org/10.1051/e3sconf/ 202017401037 (дата обращения 15.10.2021).

8. Qiu D., He Y., Yu Z. Investigation on compression mechanical properties of rigid polyurethane foam treated under random vibration condition: an experimental and numerical simulation study // Materials. - 2019. - V. 12 (20). DOI $10.3390 /$ ma12203385

9. Practical investigations into resin anchored roof bolting parameters J. Purcell, D. Vandermaat, M. Callan, P. Craig // Proc. of the 16th Coal Operators' Conference, Mining Engineering. - 2016. - P. 53-63.

10. Bierman R., Gardner L., Piper P. An evaluation of the bond strength of multiple resin bolt and capsule combinations through laboratory testing and applied methodologies // Deep Mining 2019: Proc. of the Ninth International Conference on Deep and High Stress Mining. - 2019. - P. 175-190. URL: https://doi org/10.36487/ACG_rep/1952_14_Bierman (дата обращения 15.10.2021).

11. Gardner L., Fox M., Conley N. Selecting support for new mine development - a case study from Impala Platinum Ltd // Proc. of the Seventh International Symposium on Ground Support in Mining and Underground Construction. - Australia: Australian Centre for Geomechanics, 2013. - P. 411-420.

12. Practical approaches to sand management / A. Acock, T. Orourke, D. Shirmboh, J. Alexander, G. Andersen, T. Kaneko, A. Venkitaraman, J. Lopez de Cardenas, M. Nishi, M. Numasawa, K. Yoshioka, A. Roy, A. Wilson, A. Twynam // Oilfield Review. 2004. - V. 16. - P. 10-27. URL: https://www.researchgate.net/
publication/288809656_Practical_approaches_to_sand_manageme nt (дата обращения 15.10.2021).

13. Yuxuan J. Quantitative study on the effect of shotcrete and anchor support considering the combined effect of surrounding rock and support. - Changsha: Hunan University, 2019. - 30 p.

14. Gale W.J., Fabjanczyk M.W., Guy R.J. Optimization of reinforcement design of coal mine roadways // Proc. of the 11th International Conference on Ground Control in Mining. Wollongong, New South Wales, Australia: University of Wollongong, 1992. - P. 272-279.

15. Esterhuizen G.S., Tulu I.B. Analysis of alternatives for using cable bolts as primary support at two low-seam coal mines // International Journal of Mining Science and Technology. 2015. - V. 16. URL: https://www.researchgate.net/publication/ 287374864_Analysis_of_alternatives_for_using_cable_bolts_as_p rimary_support_at_two_low-seam_coal_mines (дата обращения 15.10.2021)

16. Xuefu Y. Axial deformation theory and basic laws of surrounding rock deformation and failure // Uranium Mining and Metallurgy. 1982. - V. 1 (1). - P. 7-14.

17. Numerical study on roadway stability under weak geological condition of PT Gerbang Daya Mandiri underground coal mine in Indonesia / P. Phanthoudeth, T. Sasaoka, H. Shimada, B. Ulaankhuu, J. Oya, S. Dwiki, T. Karian // GSTF Journal of Geological Sciences (JGS). - 2016. - V. 3. - № 1. - P. 15-23. DOI: 10.5176/2335-6774 3.1.26.

18. Zhu W., Xu J., Xu G. Mechanism and control of roof fall and support failure incidents occurring near longwall recovery roadways // The Journal of the Southern African Institute of Mining and Metallurgy. - 2017. - V. 117. - № 11. - P. 1063-1072. DOI: $10.17159 / 2411-9717 / 2017 / \mathrm{v} 117 \mathrm{n} 11 \mathrm{a} 11$.

19. Karampinos E., Hadjigeorgiou J., Pierce M. Explicit representation of rock reinforcement in 3D DEM models for foliated ground // The Journal of the Southern African Institute of Mining and Metallurgy. - 2018. - V. 118. - № 12. - P. 1243-1250. DOI: 10.17159/2411-9717/2018/v118n12a2.

20. Временное руководство по упрочнению неустойчивого горного массива нагнетанием фенолформальдегидного состава на шахтах Кузбасса. - Прокопьевск: Куз-НИУИ, 1991. - 36 с.

Поступила 17.12.2021 2.

\section{Информация об авторах}

Цибаев С.C., кандидат технических наук, доцент кафедры разработки месторождений полезных ископаемых Кузбасского государственного технического университета имени Т.Ф. Горбачева.

Зорков Д.В., кандидат технических наук, доцент кафедры разработки месторождений полезных ископаемых Кузбасского государственного технического университета имени Т.Ф. Горбачева,.

Ренев $\boldsymbol{A}$.A., доктор технических наук, профессор, заведующий кафедрой разработки месторождений полезных ископаемых Кузбасского государственного технического университета имени Т.Ф. Горбачева

Ванг Цин, профессор, государственная лаборатория предотвращения и контроля катастроф в горном деле Шаньдунского научно-технического университета. 
UDC: 622.267 .7

\title{
FEATURES OF APPLICATION OF POLYMER AND ORGANIC FASTENING COMPOUNDS IN UNDERGROUND MINING WORKINGS REPAIR OPERATIONS
}

\author{
Sergey S. Tsibaev 1 , \\ cibaevss@kuzstu.ru
}

Danil V. Zorkov 1 , zorkovdv@kuzstu.ru

Alexey A. Renev ${ }^{1}$, Traa@kuzstu.ru

Qing-duo Wan², qwang@sdust.edu.cn

1 T.F. Gorbachev Kuzbass State Technical University, 28, Vesennyaya street, Kemerovo, 650000, Russia.

2 State Key Laboratory of Mining Disaster Prevention and Control Co-founded by Shandong Province and the Ministry of Science and Technology, Shandong University of Science and Technology, 579, Qianwangang Road, Huangdao District, Qingdao, Shandong Province, 266590, China.

The relevance. Nowadays the special fastening compounds and technologies are widely used to increase the roof and walls rock stability, fill visible open cracks and voids. It can prevent rock or coal collapses and dumps during the repair operations into underground mine workings. The rock chemical fastening technology has been successfully used in Russian and foreign coal mines for over 30 years. The main idea of this technology is bonding unstable massif areas with special compounds. The application area of fastening compounds is very wide. It is well known that the presence of roof and walls rock falls leads to formation of domes, a significant increase in the height of mine workings and to formation of deep coal squeezing in the walls. The presence of domes collapses and deep squeezes are the places of methane accumulations in high workings. It has a current interest in mining when fastening compositions form the new technics for mine workings repair operations.

The main aim is rock massif fastening parameters and design solutions development using modern fastening compounds during the repair and recovery of mine workings.

Methods: field measurements, statistical processing of results.

Results. The paper considers a fastening compounds complex review during the mine workings repair operations. A comprehensive analysis of different fastening compounds in terms of the main bonding component was carried out. It took into account fastening compounds technical characteristics, their application areas and equipment requirements. Eight main groups of compounds were allocated. A technological scheme at workings crossway areas for roof and walls rock fastening using polyurethane compounds injection was proposed.

\section{Key words:}

Mine workings stability, mine workings repair, anchorage, fastening compounds, chemical fastening.

The research was finacially supported by the State task of the Ministry of Science and Higher education of the Russian Federation (no. 075-03-2021 138/3).

\section{REFERENCES}

1. Tsibaev S.S., Renev A.A., Qing-duo Wan, Feng-hai Yu. Typical forms surrounding rock massif deformations analysis for mine workings support recovery. Bulletin of the Tomsk Polytechnic University. Geo Assets Engineering, 2021, vol. 332, no. 11, pp. 223-232. In Rus.

2. Tsibaev S., Renev A., Zainulin R., Kucherenko A. Analysis of rock mass and anchor support elements deformations during the long-term maintenance of mine workings. $V^{\text {th }}$ International Innovative Mining Symposium, 2020, vol. 174. Available at: https://doi.org/10.1051/e3sconf/202017401001 (accessed 15 October 2021).

3. Renev A., Tsibaev S., Kalinin S. The evaluation of negative anthropogenic factors subjection on bolts stability and surrounding massif deformations. $9^{\text {th }}$ China-Russia Symposium. Coal in the $21^{\text {st }}$ Century: Mining, Intelligent Equipment and Environment Protection. 2018. pp. 359-364. Available at: https://doi.org/ 10.2991/coal-18.2018.67 (accessed 15 October 2021).

4. Snuparek R., Soucek K. Polyurethane geocomposites. mechanical properties and deformation. International Mine Water Association Proceedings. Sevilla, Spain, 1999. pp. 657-661.
5. Shreedharan S., Kulatilake P.H.S.W. Discontinuum - equivalent continuum analysis of the stability of tunnels in a deep coal mine using the distinct element method. Rock Mechanics and Rock Engineering, 2016, no. 49 (5), pp. 1903-1922. Available at: https://www.researchgate.net/publication/284103706_Discontinuu m-Equivalent_Continuum_Analysis_of_the_Stability_of_Tunnels in_a_Deep_Coal_Mine_Using_the_Distinct_Element_Method (accessed 15 October 2021).

6. Sabri M.M., Shashkin K.G. Improvement of the soil deformation modulus using an expandable polyurethane resin. Magazine of Civil Engineering, 2018, vol. 83 (7), pp. 222-234. DOI: 10.18720/MCE.83.20

7. Filimonov K., Zorkov D., Tsibaev S., Kucherenko A. Rock pressure manifestation in development workings advanced in a thick coal seam. $V^{\text {th }}$ International Innovative Mining Symposium. 2020. Vol. 174. Available at: https://doi.org/10.1051/e3sconf/ 202017401037 (accessed 15 October 2021).

8. Qiu D., He Y., Yu Z. Investigation on compression mechanical properties of rigid polyurethane foam treated under random vibration condition: an experimental and numerical simulation study. Materials, 2019, vol. 12 (20). DOI: 10.3390/ma12203385 
9. Purcell J., Vandermaat D., Callan M., Craig P. Practical investigations into resin anchored roof bolting parameters. Proc. of the $16^{t}$ Coal Operators' Conference, Mining Engineering, 2016, pp. 53-63.

10. Bierman R., Gardner L., Piper P. An evaluation of the bond strength of multiple resin bolt and capsule combinations through laboratory testing and applied methodologies. Deep Mining 2019: Proc. of the Ninth International Conference on Deep and High Stress Mining. 2019. pp. 175-190. Available at https://doi.org/10.36487/ACG_rep/1952_14_Bierman (accessed 15 October 2021)

11. Gardner L., Fox M., Conley N. Selecting support for new mine development - a case study from Impala Platinum Ltd. Proc. of the Seventh International Symposium on Ground Support in Mining and Underground Construction. Australia, Australian Centre for Geomechanics, 2013. pp. 411-420.

12. Acock A., Orourke T., Shirmboh D., Alexander J., Andersen G., Kaneko T., Venkitaraman A., Lopez de Cardenas J., Nishi M., Numasawa M., Yoshioka K., Roy A., Wilson A., Twynam A. Practical approaches to sand management. Oilfield Review, 2004 vol. 16, pp. 10-27. Available at: https://www.researchgate.net/ publication/288809656_Practical_approaches_to_sand_manageme nt (accessed 15 October 2021).

13. Yuxuan J. Quantitative study on the effect of shotcrete and anchor support considering the combined effect of surrounding rock and support. Changsha, Hunan University, 2019. pp. 11-30.

14. Gale W.J., Fabjanczyk M.W., Guy R.J. Optimization of reinforcement design of coal mine roadways. Proc. of the $11^{\text {th }}$ International Conference on Ground Control in Mining. Wollongong, New South Wales, Australia, University of Wollongong, 1992. pp. 272-279.

15. Esterhuizen G.S., Tulu I.B. Analysis of alternatives for using cable bolts as primary support at two low-seam coal mines. International
Journal of Mining Science and Technology, 2015, vol. 16. Available at: https://www.researchgate.net/publication/287374864_ Analysis_of_alternatives_for_using_cable_bolts_as_primary_support_at_t wo_low-seam_coal_mines (accessed 15 October 2021).

16. Xuefu Y. Axial deformation theory and basic laws of surrounding rock deformation and failure. Uranium Mining and Metallurgy, 1982, vol. 1 (1), pp. 7-14.

17. Phanthoudeth P., Sasaoka T., Shimada H., Ulaankhuu B., Oya J., Dwiki S., Karian T. Numerical study on roadway stability under weak geological condition of PT Gerbang Daya Mandiri underground coal mine in Indonesia. GSTF Journal of Geological Sciences (JGS), 2016, vol. 3, no. 1, pp. 15-23. DOI: 10.5176/233567743.1 .26 .

18. Zhu W., Xu J., Xu G. Mechanism and control of roof fall and support failure incidents occurring near longwall recovery roadways. The Journal of the Southern African Institute of Mining and Metallurgy, 2017, vol. 117, no. 11, pp. 1063-1072. DOI: 10.17159/2411-9717/2017/v117n11a11

19. Karampinos E., Hadjigeorgiou J., Pierce M. Explicit representation of rock reinforcement in 3D DEM models for foliated ground. The Journal of the Southern African Institute of Mining and Metallurgy, 2018, vol. 118, no. 12, pp. 1243-1250. DOI: 10.17159/24119717/2018/v118n12a2.

20. Vremennoe rukovodstvo po uprochneniyu neustoychivogo gornogo massiva nagnetaniem fenolformaldegidnogo sostava na shahtakh Kuzbassa [Temporary guide for unstable rock mass fastening using injection of phenol-formaldehyde composition in conditions of Kuzbass coal mines]. Prokopevsk, KuzNIUI Publ., 1991. 36 p.

Received: 17 December 2021.

\section{Information about the authors}

Sergey S. Tsibaev, Cand. Sc., associate professor, T.F. Gorbachev Kuzbass State Technical University.

Danil V. Zorkov, Cand. Sc., associate professor, T.F. Gorbachev Kuzbass State Technical University.

Alexey A. Renev, Dr. Sc., professor, head of the department, T.F. Gorbachev Kuzbass State Technical University.

Qing-duo Wan, State Key Laboratory of Mining Disaster Prevention and Control Co-founded by Shandong Province and the Ministry of Science and Technology, Shandong University of Science and Technology. 